\title{
LA PARTIDA DE BAUTISMO Y OTROS DATOS INÉDITOS PARA LA BIOGRAFÍ DEL POETA ÁUREO SEVILLANO HERNANDO DE SORIA GALVARRO. (UN CASO MÁS DE UN ESCRITOR EN EL SENO DE UNA FAMILIA DE COMERCIANTES INDIANOS)
}

\author{
Mercedes Cobos \\ Universidad de Sevilla. España
}

Además de aportar algunos nuevos datos de interés general para la biografía de este autor, como son el lugar y fecha de su bautismo, y otras noticias relativas tanto a la rama materna como paterna de su familia, desconocidas hasta el momento, pretendemos poner de manifiesto una vez más un aspecto muy concreto de las complejas y múltiples relaciones que se establecen entre España e Indias durante los siglos XVI y XVII, ofreciendo, como ya hiciéramos en uno de los trabajos que dedicamos a otro poeta sevillano, Juan de Jáuregui ${ }^{1}$, un nuevo ejemplo de cómo debieron ser precisamente los beneficios obtenidos con el comercio con el Nuevo Mundo, actividad tan denostada por la poesía filosófico-moral del Siglo de Oro de las letras españolas, los que posibilitaron la esmerada formación de no pocos de nuestros escritores de ese período, que no por ello dejaron de hacerse eco de ese lugar común de la poesía de contenido ético del Seiscientos que es la censura contra las navegaciones a Indias, como es el caso de Jáuregui.

Pero el de Soria Galvarro ofrece algunas particularidades, pues si en cierta medida su caso se asemeja al de otros autores de la época como ejemplo de escritor surgido en el seno de una familia de mercaderes indianos, el mismo poeta explica en una epístola a su primo Lucas de Soria cómo se vio 
afectada su vida por la posterior ruina de su padre, que le impidió llevar a la práctica el ideal de vida al que dice aspirar, y que no es otro que el propugnado por la poesía filosófico-moral de la época, esto es, el retiro, que contrapone a la corte, en su caso, pontificia, a la que se vio avocado por las circuntancias:

Segunda vez a ver de Roma el muro bueluo, o Lucas, dudoso peregrino del hado y de la suerte mal seguro

A començar de aqui nueuo camino y aquella senda que seguir me ordena la inexorable lei de mi destino

Tu la as jusgado necessaria y buena, $y$ yo tambien la jusgo necessaria mas no que de trabajos este llena.

Quien piensa que natura es tributaria de la purpura $y$ ostro les incline vna y otra rodilla voluntaria

$\mathrm{Y}$ a estos idolos tanto se avezine que se tenga por bien afortunado quando entre abrojos de dolor camine.

Mas quien de mejor luz nacio guiado $y$ de las cosas la verdad alcança no como el vulgo de hombres engañado

Que hara en los palacios? que esperança? digo que no dudosa sino cierta hara torcer el fiel de su balança?

Yo entre a este laberinto por la puerta al fin que saues bien; para que entrase se me mostro de par en par abierta.

No quisiera que dentro me faltase la cuerda que dexe al entrar assida para que en estos giros me guiase.

Fue vn laberinto hasta aqui mi vida donde en manos del caso emos corrido a suelta rienda calles sin salida

$\mathrm{Y}$ a lo postrero de el emos venido en otro mas robusto e intricado do por oculta fuerza fui traido. (...)

Pero lo que tu primo aora mas siente es verse començar esta carrera quando no pocas canas ve en su frente.

$y$ que cuando buscar puesto ${ }^{2}$ quisiera para la Nauichuela combatida lexos se ue engolfar de la ribera. 
esta mi vida para que es guardada primo, a qual fin la tiene o paradero

la lei del hado mio destinada? este mi ingenio candido y sincero que tal lo as siempre tu, $y$ otros jusgado, y culpado tal vez de verdadero, quando supo mentir? quando a callado el mas interno affecto que del seno no lo vuiesse a la frente trasladado? para la vida de palacio es bueno donde es primer dogma el artificio y el semblante de astucia y fraude lleno. no puede a tales cosas mi juiçio aplicarse jamas, ni aunque gustara diestro salir pudiera en este officio, imposible es no verseme en la cara hasta el menos affecto $y$ la sentencia de la alma escrita alli muy a la clara. Diras que es vn linaje de imprudencia que mereçe otro nombre, yo confiesso que es assi, $y$ que as jusgado con clemencia mas aunque lo conosco no por ${ }^{3}$ esso puedo formar mi condicion, ni a sido en mi poder mudar de ella o de seso

No se viuir no se viuir, uencido ya me confieso a las dificultades del siglo mentiroso en que e nacido.

(...) mas agora que nunca, yo e sembrado a costa de sudor penas y enojos.

$$
\text { (...) si la estrecheza }
$$

en que dexo mi padre mi fortuna reducida a la vltima pobreza; pudiese prometerte ${ }^{4}$ auer alguna pequeña renta, tal que ni sobrasse ni a puerta de otros me lleuase aiuna a mis votos el cielo conformasse algun dia el susseso y concediera que a $\mathrm{mi}$ arbitrio el viuir mio guiase.

$\mathrm{Si}$ a los postreros tercios permitiera de vna vida quiça desengañada que el sitio y la viuienda se escogiera; no pienses que de mi fuera buscada Seuilla, o Roma a mis postreros años ni que en Madrid hiziera mi morada. borraron de alli el gusto dessengafios de la madura edad que no consiente 
tanto reino al error de los engafios

agora voluntad ya differente

de las cortes me aparto (...)

(...)

Si a mi desseo se mostrasse auierta

la puerta que aora digo, y me hallara

con alguna rentilla o pinsion cierta

vna pequefia aldea yo buscara

vezina a la ciudad, o algun conuento

do la vejez que viene me hallara,

$y$ en soledad y dulçe apartamiento

en vn ocio estudioso repartiera

las horas y los dias bien contento. 5

Aunque no puede ignorarse que se trata de un lugar común del pensamiento de finales del siglo XVI y del XVII, producto del resurgir de la filosofia estoica, que, junto a la mencionada denostación contra las navegaciones, especialmente las inducidas por la codicia, echa mano del viejo tópico del menosprecio de corte y alabanza de aldea, ni que fueron muchos los humanistas y escritores barrocos que alabaron y propugnaron este ideal de vida, pero muy pocos los que lo siguieron, debe tenerse en cuenta que algunos pasajes de esta epístola a su primo Lucas son claramente autobiográficos $y$, como se podrá ir comprobando a lo largo de este estudio, los datos en ellos contenidos suelen responder a la realidad. "A mi -escribe en esta misma composición- (...) no consiente/ mi condicion mentir, ni hazer engaños, ni del que soy pintarme diferente» ${ }^{6}$.

Por otra parte - como hemos estudiado en otro lugar ${ }^{7}$-, Soria Galvarro resulta ser el autor que desde España escribe la más elogiosa y lograda composición heroica ${ }^{8}$ de asunto americano - de las que se tiene noticia hasta el momento-: la extraordinaria Silva de la nao Victoria, con la que logra, como pocos, dar altura poética a un episodio de la gesta americana: el del hallazgo del estrecho de Magallanes y la primera vuelta al mundo, si bien parece seguir una tradición de admiración por los descubridores más que por los conquistadores, que tiene su origen en el humanismo del Quinientos. En 1966, al editar esta silva y la citada epístola, hasta entonces inéditas, Antonio Rodríguez Monino se lamentaba de que «la parvedad de su obra conocida no ha estimulado a los comentaristas el deseo de acopiar notas para tejer una narración biográfica». Y añadía: "Al ordenar estas notas biográficas y al imprimir los dos poemas que ven la luz por primera vez, intentamos estimular a los investigadores sevillanos y cordobeses para que lleven a cabo en los respectivos archivos locales una búsqueda de lo mucho que aún debe estar en ellos enterrado y que contribuirá a aclarar la biografía de un poeta que se nos revela como muy digno de estudio y consideración" ${ }^{2}$. Dado que - que sepa- 
mos- la erudición posterior parece haber ignorado la razonable propuesta que hiciera este estudioso, hemos emprendido dicha investigación con la esperanza de que en alguna medida podremos contribuir a reconstruir la biografía de este gran poeta sevillano ${ }^{10}$. El presente trabajo recoge los datos que hemos reunido hasta el momento.

Sus abuelos y bisabuelos paternos recibieron sepultura en la iglesia de San Salvador de Sevilla, al igual que una de sus tías paternas, María de Soria, que falleció entre el 20 de noviembre de 1590 y el 9 de enero de 1591 . Además de ésta, que permaneció soltera, el padre de nuestro autor tenía al menos dos hermanas más, llamadas Leonor y Beatriz. Por su testamento, otorgado el 20 de noviembre de 1590 en casa del padre del escritor, María nombraba sus albaceas testamentarios a éste y a otro hermano del que ya se tenía notocia, Pedro Fernández de Soria, y legaba a Lucas, hijo del último, una partida de tributo de 400 ducados de principal ". Si sobre el padre del poeta, Hernando de Soria, se sabía poco más que el cargo que ostentaba, tesorero de la Casa de la Moneda de Sevilla, y que era hombre dedicado a "negocios varios»" ${ }^{12}$, sobre su madre ignorábase todo, incluso el nombre, María de Jaso, que ahora conocemos por la partida de bautismo de nuestro autor, la cual hemos hallado siguiendo sus propias indicaciones en la citada epístola, en las que ningún estudioso, ni siquiera Rodríguez Moñino, parece haber reparado:

La mas parte a cogido de la vida la aspa de Cloto, aunq esta se alegrara 13 hasta vejez a pocos concedida

Si en San Miguel alguno me contara los años del bautismo, de quarenta desde Febrero aca se que pasara

Auer viuido tienen por afrenta a los que oy sirue el orbe, o que les miente quiça la tinta, $y$ ierran en la quenta

A mi aunque no fuera aio no consiente mi condicion mentir, ni hazer engaños, ni del que soy pintarme diferente ${ }^{14}$

Efectivamente, Hernando de Soria Galvarro, hijo de Hernando de Soria y de María de Jaso, "su mujer", fue bautizado en la parroquia de San Miguel de Sevilla el 28 de febrero de 1573, siendo su padrino cierto Antonio Enríquez Pimentel, vecino de la ciudad de Santo Domingo ${ }^{15}$. Este Antonio Enríquez Pimentel pasaría más tarde a la corte, en la que se hallaba en 1586 y a la que le habían llevado sus pretensiones de un oficio en Indias y tal vez la consecución del hábito de San Juan, a cuya orden pertenecía ya en esta fecha. Convertido durante nueve años en uno de tantos pretendientes, el 11 
de julio de 1586 eleva un memorial al Rey en el que dice haber solicitado el puesto de general de las galeras de la guarda de las Indias, el gobierno de la isla de Cuba o el corregimiento del Cuzco o de Méjico y otras plazas - que no precisa - sin que hasta la fecha se hubiese tomado resolución sobre ello y suplica que se haga brevemente porque padece extrema necesidad y no puede sustentarse en la corte. Remitido el memorial al Consejo de Indias, responde que las leyes no permiten que los caballeros del hábito de San Juan accedan a cargos de gobierno y justicia, como en otras ocasiones se la había dado a entender al solicitante, y que no se han ofrecido cosas de guerra en qué ocuparle, aconsejando que su petición se remitiera al Consejo de Guerra ${ }^{16}$. Finalmente se le hizo merced del oficio de capitán y cabo de las galeras de la guarda de las Indias, según consta en la relación de servicios de uno de sus sobrinos, llamado Francisco Enríquez Pimentel, natural de Santo Domingo, nieto de Pedro Serrano de la Drada, contador de la Real Hacienda y chanciller de la Audiencia de la isla de Puerto Rico, y de doña Isabel Enríquez Pimentel, hermana del padrino del poeta, naturales ambos de Santo Domingo, y biznieto de Juan de Castellanos, primer tesorero de la Hacienda Real de dicha isla, y de doña Ana de Pimentel, su mujer, hija legítima de Francisco Pimentel, señor de la casa y mayorazgo de las villas de Rivera y Grajal, en Valladolid ${ }^{17}$. Consérvanse dos informes, al parecer de 1521 —aunque la datación no es segura-, sobre la conveniencia de formar en la isla Española un único puerto de los dos existentes, Monte Cristi y Puerto Real, y que para guardarlo hubiera cuatro galeras, dados, a petición del cardenal Tortosa, por cierto Antonio Enríquez Pimentel, del que por ahora no tenemos datos suficientes para asegurar que se trate del padrino del escritor ${ }^{18}$.

Del matrimonio de Hernando de Soria y María de Jaso nació al menos otra hija, llamada Ángela de Jaso - de la que da noticia Antonio Herrera García, aunque sin sospechar que se trata de la hermana del poeta-, que en 1612 era monja en San Clemente el Real ${ }^{19}$. El 19 de julio de 1576 fue bautizado, también en San Miguel, Juan, hijo de Hernando de Soria y de María Galvarro, "su legítima muger» ${ }^{20}$. Esta María Galvarro era hermana de Isabel Galvarro, la esposa de Pedro Fernández de Soria, padre no sólo del destinatario de la epístola - como es bien sabido ${ }^{21}$ - , sino también de otros ocho primos del escritor ${ }^{22}$. Debemos suponer que se trata de una nueva esposa del padre de nuestro autor ${ }^{23}$, pero es de notar que éste toma como segundo apellido "Galvarro" y no "Jaso". Con él aparece ya en un documento del 16 de diciembre 1589: la partida de bautismo de un niño, llamado Pedro, hijo de cierto Diego Rodríguez y de María Rodríguez, su mujer, que recibió dicho sacramento en la parroquia de San Miguel, siendo su padrino el vecino de aquella collación "Hernando de Soria Galbarro» ${ }^{24}$. Sabemos de la existencia 
de otras dos hijas de Hernando de Soria, aunque en ambos casos desconocemos sus nombres. Una de ellas - de la que también nos da noticia Antonio Herrera García - casó con cierto Juan Felipe de Córdoba ${ }^{25}$. La otra, con un tal Hernán Ramírez de Molina. Parece que esta última había fallecido ya en 1598 , cuando su marido contaba unos cincuenta años ${ }^{26}$.

Tal vez sea en las relaciones comerciales con Santo Domingo de Juan Galvarro, padre de María e Isabel, donde debamos buscar la explicación de la vecindad del padrino del poeta. Por lo que toca a los Jaso, aunque hemos localizado algunos individuos con este apellido - no muy frecuente-, no tenemos constancia de que estén emparentados con nuestro autor. Esperemos que posteriores investigaciones aporten más datos sobre esta rama de su familia. Respecto a los Galvarro podemos decir que Juan Galvarro había fallecido ya antes de que aquél naciera. Exactamente, el martes 8 de julio de 1551, en sus casas de la collación de San Salvador ${ }^{27}$, en las que su mujer, Isabel de Herrera, segula viviendo con los hijos de ambos años después. Dos días antes, el domingo 6 de julio de 1551, había otorgado testamento cerrado ${ }^{28}$. Por él dejaba por sus herederos a partes iguales a sus hijos Antonio, María, Leonor, Ana, Diego e Isabel, que, según se dice, por entonces contaban doce, diez, siete, cuatro, tres y un años respectivamente, así como a la criatura o criaturas de la/s que a la sazón estaba preñada su esposa. Cinco de ellos fueron bautizados en la parroquia sevillana de San Salvador: Antonio, el 12 de febrero de 1538 ${ }^{29}$; Maria, el 8 de diciembre de 153930; Ana, el 24 de abril de $1546^{31}$; Isabel, el 21 de septiembre de $1549^{32}$; y el póstumo, una niña que recibió el nombre de Juana, el 19 del mismo mes de $1550^{33}$. Como albaceas designaba a la dicha Isabel de Herrera, a ciertos Juan Hurtado y Andrés Pérez y a su sobrino Melchor de Mújica. Y por tutora de los dichos menores, a su mujer, "[...] a la qual —dice- pido e suplico, por amor de Dios e por la buena conpañía que la hize e la desehé fazer, críe sus hijos en buena dotrina, mirando que vale mucho más que queden vien yndustria(na)dos que ricos. Y quiero - continúa - y es mi boluntad que sea señora e administradora de toda la hazienda de los $\mathrm{d}[\mathrm{ic}]$ hos mis hijos, tratando por mar e por tierra con parecer de mis albaçeas e de qualquier de los de quien yo hago entera confiança [...]). La misma esposa confirma que a la muerte de su marido quedaron ciertos bienes muebles y raíces y derechos y acciones. El 9 de dicho mes y año, es decir, el día siguiente al fallecimiento de su marido, Isabel de Herrera fue confirmada como tutora y curadora de las personas y bienes de todos sus hijos al ser éstos aún menores de edad y el mismo día tuvo lugar la aceptación de herencia por parte de éstos.

En cierta información, practicada en Sevilla el 10 de abril de 1551, uno de los testigo dice conocer a Juan Galvarro desde diez años antes de que 
falleciera en 1550 y a su mujer, de más de ocho años. Por su parte, Gaspar Jorge, de treinta y cuatro años de edad, mercader y vecino de Sevilla en la collación de San Nicolás, asegura haber sido compadre del difunto, al que conocía desde hacía diez anios poco más o menos. En otra, llevada a cabo en la misma ciudad el 19 de abril de 1553, éste dirá únicamente que conocía a Juan Galvarro desde hacía más de ocho años. En la misma probanza, la mujer de un zapatero, vecina de Sevilla en la collación de San Salvador, declara conocer a Isabel de Herrera desde hacía unos veinte años y a Juan Galvarro, durante unos nueve, desde que se casó con la dicha Isabel de Herrera, podría hacer unos trece años, hasta que falleció; y que conocía a todos sus hijos porque los vio nacer $y$ criarse. $Y$ asimismo depuso que "[...] vido que los trayan vna madrugada de velar de la yglesia de San Salbador desta $\mathrm{d}[$ ic] ha çibdad e vido $\mathrm{q}$ [ue] fueron sus padrinos don Rodrigo de Sosa, difunto, $\mathrm{y}$ doña Juana de Guzmán, su muger. E el día de la velaz[i]ón este t[estig]o comyó de la fruta que se rrepartió en su casa e después este $t$ [estig]o les vido hazer vida maridable muy católicamente como muy buenos cristianos, como marido y muger legítimos, estando juntos en vna casa que es en esta $\mathrm{d}$ [ic] ha çibdad de Sevilla en la collaçión de San Salbador en la calle que dizen del peladero de los puercos y en posesyón de casados e velados este $t$ [estig]o los tovo e fueron tenydos. Esto es muy pú[bli]co entre las personas que lo saben e los conoçieron [...]». La mujer de otro zapatero, vecina de la misma collación, afirma conocer a Isabel de Herrera desde hacía unos veinte y cinco años y a todos los hijos de ésta y de Juan Galvarro, al que, así como la anterior testigo, dice haber conocido durante unos nueve, desde que se casó con la dicha Isabel de Herrera hasta que falleció, confirmando también que desde que se casaron "[...] puede aver treze años, poco más o menos. $\mathrm{E}$ que este testigo vido que se casaron e velaron los $\mathrm{d}$ [ic] hos Juan Galbarro e doña Ysabel de Herrera, su muger. $\mathrm{E}$ al tiempo que se belaron este $\mathrm{t}$ [estig]o, estando en su casa parada en una su bentana, que salía a la calle, los vido yr a belar e, después, los vido venyr velados. E vido que fueron sus padrinos don Rodrigo de Sosa, difunto, y doña Juana de Guzmán, su muger, vez[in]os desta cibdad. E después este testigo les vido pú[bli]cam[en]te hazer vida maridable en vno como marido e muger legítimos, estando juntos en su casa, que es en esta çibdad en la d[ic]ha collaçión de San Salbador al peladero que dizen de los puercos, como muy buenos christianos, porque tal lo era el $\mathrm{d}[\mathrm{ic}]$ ho Juan Galvarro e lo es la d[ic] ha donia Ysabel de Herrera, su mujer. E este testigo les vido que se nombraban por tales marido e muger legítimos. $E$ esto es ansy público e notorio en esta cibdad entre las personas que lo saben [...]». Sin embargo, repárese en que, si tomamos al pie de la letra la información ofrecida por estas dos declarantes en relación a la fecha en que contrajeron matri- 
monio Juan Galvarro e Isabel de Herrera, ello supondría que su hijo Antonio y tal vez también su hija María - la segunda esposa de Hernando de Soria, nacidos a principios de 1538 y finales de 1539 respectivamente, habrian sido concebidos fuera del matrimonio. No así, si se considera que los trece años han de contarse no hasta fecha de la probanza (1553), sino hasta la de la muerte de Galvarro (1551). Por el momento no nos es dado aclarar este punto, ya que no es posible localizar los documentos relativos a dichos esponsales, pues en el Archivo Parroquial de San Salvador no se conservan los libros de matrimonios anteriores al año 1563, pero es de notar que en las correspondientes partidas de bautismo ambos hermanos están consignados como hijos de Juan Galvarro y doña Isabel de Herrera, «su muger».

Al parecer, por las fechas de su fallecimiento Juan Galvarro era jurado de la ciudad de Sevilla ${ }^{34}$. A lo largo de su vida había desempeñado algún otro cargo, como el de correo mayor de dicha ciudad, que parece ostentaba al menos desde $1536^{35}$, pero, sobre todo, una intensa actividad mercantil con el Nuevo Mundo. El 11 de marzo de 1536 se le concedía permiso para enviar a Indias una esclava a cierto Diego de Verdejo ${ }^{36}$. El 11 de diciembre de dicho año se le da licencia para llevar al mismo destino 49 esclavos negros, libres de derechos, en pago y a cambio de los 14.000 maravedís que por mandato real le tomaron los oficiales de Sevilla sobre cierta cantidad de oro y plata que le había sido enviada desde las Indias ${ }^{37}$. El 26 de septiembre de 1539 una tal Leonor Rodríguez da poder a cierta persona residente en Méjico y a Juan Galvarro, al que llama "mercader" y del que dice es vecino de Sevilla en la collación de San Salvador, para que le cobren la herencia que le correspondía por la muerte de su padre, fallecido en Nueva España. Por tres poderes relativos a este asunto, otorgados por Juan Galvarro en 1543, parece que seguía siendo vecino de dicha collación ${ }^{38}$. Así lo confirma también el hecho de que el 1 de enero de ese mismo año se bautizaran en dicha parroquia 3 esclavos negros de su propiedad ${ }^{39}$. Por otra parte, en 22 de enero de ese mismo año se le había vuelto a dar autorización para pasar a Indias otros 100 esclavos negros ${ }^{40}$ y en agosto se le concedería que pudiera pasar 50 más ${ }^{41}$. En febrero aparece de nuevo como mercader y vecino de Sevilla en la apelación que eleva al Consejo de la sentencia dictada por los jueces de la Audiencia de la Contratación en el pleito que contra él había seguido Diego de Baeza, también mercader y vecino de Sevilla, sobre la entrega de una partida de plata registrada por bienes de la dicha Leonor Rodríguez de Zazarabaza para satisfacción de la deuda que ésta tenía contraída con ambos. El pleito se prolongaría hasta $1547^{42}$. En 19 de octubre obtiene una nueva licencia para pasar a Indias 50 nuevos esclavos negros ${ }^{43}$. El 7 de diciembre se le permite que pase otros $50^{44}$. Del año siguiente es una real cédula en la que se recoge la capi- 
tulación tomada con Juan Galvarro, correo mayor de Sevilla, y sus consortes sobre algunas cantidades de coral que había en ciertos lugares de las Indias. Como para dicha empresa era necesaria abundante mano de obra, se les da licencia para que puedan enviar 100 esclavos negros a cualquier parte de ellas, advirtiendo "que no pueda entender en ello ningún yndio porque no sean maltratados en la dicha grangería, como lo han sido los que han entendido en la pesquería de las perlas»" ${ }^{45}$. De 16 de mayo de 1548 es la real cédula por la que se hace efectiva la licencia a Juan Galvarro, que vuelve a aparecer con el cargo de correo mayor de Sevilla, y a sus consortes, Gaspar Jorge y Juan García, mercaderes, vecinos de Sevilla, para pasar los dichos 100 escla$\operatorname{vos}^{46}$. Recuérdese que tres años después, en 1551, tras la muerte de Galvarro, Gaspar Jorge declarará haber sido compadre del difunto. Por otra real cédula del 6 de diciembre de ese mismo año se prohibe que cualquier otra persona que no sea Juan Galvarro y otros con los que se había tomado capitulación al respecto pueda emplearse en el descubrimiento del coral de las Indias durante 1548 y $1549^{47}$. El 9 de noviembre del año siguiente obtiene autorización para enviar a Nueva España dos arneses a cierto Antonio Jiménez ${ }^{48}$. Y el 6 de diciembre del dicho año se le permite llevar a Indias 50 esclavos negros más ${ }^{49}$. Algo antes de julio de 1550 Juan de Córdoba, vecino de la ciudad que llevaba por apellido —quizás algún familiar de Juan Felipe de Córdoba, el futuro marido de una de las hermanas del poeta-, se concierta con Juan Galvarro, vecino de Sevilla, para que éste le cobre en Nueva España cierta cantidad que había heredado. En una escritura sin fechar, relativa al mismo asunto, aunque claramente algo posterior a la de julio de 1550 - como se deduce de su contenido- se dice que Juan Galvarro, correo mayor de la ciudad de Sevilla, es ya difunto ${ }^{50}$, lo cual concuerda con la fecha de fallecimiento del padre de María e Isabel que nos revelan otros documentos. El mismo año de su fallecimiento Galvarro había registrado 141 piezas de esclavos libres de derechos para Santo Domingo, sobre algunas de las cuales hubo de entablar un pleito con el fiscal de Su Majestad que, tras su muerte, continuaron su esposa e hijos y que aún sostenían en $1553^{51}$.

Por una carta de pago otorgada por Isabel de Herrera, de la que no nos consta la fecha por hallarse incompleta, pero que con toda seguridad es posterior al 8 de julio de 1551 - fecha en que, como se ha visto, fallece Galvarro, del que se dice en ella que es ya difunto-, tenemos noticia de que el marido de ésta y cierto Juan Cano tenían compañía en el trato de Indias y de que a la muerte de aquél ésta envió a un hermano del dicho Juan Cano, residente en la ciudad de Méjico, 2.000 ducados de oro que montaban los 750.000 maravedís que correspondían a Cano del caudal y ganancias de la dicha compañía ${ }^{52}$. El miércoles 22 de abril de 1551, esta misma, en su cali- 
dad de curadora de los bienes de sus hijos menores, herederos de su marido, otorga poder a Diego Fránquez, escribano público de la ciudad de San Juan de Puerto Rico, y a Luis Sánchez, mercader, estante en la de Santo Domingo, para que cobren todas las mercaderías, esclavos, bestias u otras cosas que Juan Galvarro hubiese enviado a Nueva España, Tierra Firme o cualquier otra parte de la Indias, así como las que habían enviado o en adelante enviaren ella o sus hijos. Y también el oro, plata, perlas, grana, cochinilla o cualquier otra mercancía que llegare para ellos a los dichos puertos, bien por ser de su propiedad o por encomienda de otras personas. Y, de la misma manera, el salario que hubiere ganado cualquiera de sus esclavos ${ }^{53}$. La actividad mercantil de Juan Galvarro fue continuada por al menos uno de sus hijos, Diego Galvarro de los Arcos, que el 29 de agosto de 1570, cuando contaba unos treinta y dos años, pasaría a Nueva España como mercader ${ }^{54}$.

Todo parece indicar que en un principio los Soria también gozaron de una situación económica desahogada. Durante años, Pedro $y$, sobre todo, Hernando contaron con esclavos a su servicio, lo que parece indicio de prosperidad ${ }^{55}$. Por otra parte, en 1590 Hernán Ramírez de Molina, tutor de su sobrino Francisco Molina, hijo de su hermano, Rodrigo Ramírez de Molina y de Isabel de Matos, presenta por su fiador en la dicha tutela, de cuantía de 600 ducados, a su suegro, que, según se dice, era rico y abonado para ello ${ }^{56}$.

Hernán Ramírez de Molina había permanecido bastante tiempo en la provincia de Tierra Firme y pasado muchos esclavos al Perú. En 1594, por intercesión suya, un tal Miguel Ochoa llevó a su cargo un esclavo del padre de nuestro autor, que huiría al naufragar el navío. En el mismo viaje Ramírez de Molina le encomendó mercaderías - ropa, almendras, azafrán, etc.- por valor de más de 25.000 pesos, las cuales se perderían ${ }^{57}$. Antonio Herrera García asegura que Lutgardo García Fuentes, estudioso del comercio indiano del siglo XVII, le hizo saber que había encontrado a los Soria como embarcadores de esclavos y otras mercancías a finales del siglo XVI ${ }^{58}$-al igual que Antono Herrera, Lutgardo García parece ignorar que estos Soria eran familiares del poeta-. Por nuestra parte podemos decir que el 23 de agosto de 1593 el padre del escritor dio poder a cierto Melchor de Valdivieso para cobrar de la Casa de la Contratación de las Indias o de cualquier maestre, dueño de nao o pasajero cualquier partida de reales, oro, plata, perlas, joyas u otras mercaderías que le hubieran venido consignadas desde las Indias" ${ }^{59}$. También Pedro Fernández de Soria tenía trato mercantil con el nuevo continente. En octubre de 1583, Miguel Jiménez Pintado pide que se le paguen los fletes por ciento veinticuatro cueros vacunos, tres cajas de azúcar y cinco quintales de cáscara de guayacán que entregó a Andrés de San Martín en nombre de Pedro Fernández de Soria. A lo que éste alega que 
Jiménez Pintado le ha dejado de entregar parte de la mercancía que para él traía registrada y que, parte de la que le ha entregado, viene dañada. El pleito está inconcluso ${ }^{60}$. Y sabido es que el 12 de septiembre de 1603 , el mismo Soria Galvarro dio poder a cierto Juan Aguilar para cobrar de la Contratación ciertas partidas de oro, plata, mercaderías, etc. ${ }^{61}$.

El 24 de enero de 1594 Hernado de Soria otorgó una escritura por la que se obligaba a que el esclavo negro que enviaba a las Indias no quedaría en la provincia de Tierra Firme en manera alguna, sino que pasaría adelante, como estaba mandado por Su Majestad, so pena de que, además de perderlo, habría de pagar 200 ducados. Asimismo se comprometía a que el maestre presentaría al dicho esclavo ante los oficiales reales de la provincia de Tierra Firme y, de vuelta del viaje, traería testimonio de ello y de haber pagado los derechos correspondientes, so pena de otros 100 ducados para la Cámara de Su Majestad. A principios de 1598, el fiscal de la Casa de la Contratación le demanda por no haber cumplido con el tenor de ella y pide que se dé mandamiento de ejecución contra sus bienes. A ello se opone Soria porque, según explica, "[...] el dicho esclavo negro que yo enbié en la dicha nao pasó de la dicha provincia de Tierra Firme y no quedó en ella, porque desta cibdad lo llevó a su cargo en la dicha nao Miguel Ochoa, que yva y fue en la mesma nao, y a él yva rregistrado para que lo llevase a las provincias del Pirú; y en el Nombre de Dios el dicho maestre se lo entregó y él lo llevó consigo a Panamá y allí lo tornó a enbarcar para la cibdad de Lima; e yendo navegando en la Mar del Sur, en el paraje de la baya de San Mateo, se perdió la dicha nao y dio al través en la costa y se huyeron della el dicho esclavo negro mío y otros dos de los que yvan en la mesma nao y nunca mas pareçieron ni pudieron ser avidos, y así lo escrivió el dicho Miguel Ochoa a Fernán Ramírez de Molina, mi yerno, por cuya mano e yntercesión yo encargué el dicho esclavo al dicho Miguel Ochoa, como consta y parece por esta carta misiva que en rasón dello escrivió el dicho Miguel Ochoa al dicho Fernán Ramírez de Molina, de que hago presentación en lo favorable y no en más. E yo no e avido ni cobrado [cosa] alguna del valor del dicho mi esclavo, mas antes, perdido el principal y costas que con él hize y no es justo que, siendo así verdad, se me pida ni pretenda llevar pena alguna, mayormente aviendo pasado, como pasó, el dicho negro de la provinçia de Tierra Firme y cumpliéndose el tenor de la obligación. Y porque se debe ansí desar, que enviando yo, como envié, el dicho mi negro con orden y todo el recabdo pusible para que pasase al Pirú y no quedase en la dicha provincia, e cumplido y cumplí con hazer de mi parte lo pusible, y proceder contra mí sería obligarme a lo que yo no pude prevenir ni estaba en mi mano y basta averlo perdido." A pesar de lo alegado por Hernado de Soria, se da mandamiento de ejecución contra sus bienes y 
el 10 de febrero se le embarga una fuente de plata por valor de 100 ducados. El 16 de ese mismo mes un escribano se persona en la Puerta de Triana, donde a la sazón estaba preso, para citarle de remate, pero la mujer del alcalde le informa que Soria había estado muy enfermo y se hallaba reposando, por lo que no se le podía hablar, y se ofrece a notificárselo ella misma. El padre del escritor insiste en que el esclavo no quedó en Tierra Firme y que allí no se deben derechos a Su Majestad por los esclavos, de manera que no habla de qué traer testimonio. La causa es recibida a prueba, como pide, y la sentencia definitiva, pronunciada el 3 de marzo, es favorable al fiscal, mandándose que se haga venta en pública almoneda de los bienes ejecutados $\mathrm{y}$, de su valor, se pague a la Real Cámara cincuenta ducados y que en el plazo de un año y medio presente el testimonio contenido en la fianza y obligación que hizo, con apercibimiento de que, pasando el dicho término, se haría el remate de los cincuenta ducados restantes. El 22 de abril, Andrés Tello, en nombre y con poder de Juan Antonio del Alcázar —el poeta-, depositario general de Sevilla y de la Casa de la Contratación, recibe de Hernando de Soria 550 reales por la anterior condena ${ }^{62}$.

Se sabla que a la muerte de Gaspar de Arguijo, el comerciante indiano padre del también poeta Juan de Arguijo, Hernando de Soriase encontraba entre sus deudores ${ }^{63}$. De 1601 son ciertos autos entre Juan de Ibarra, vecino de Madrid y secretario de Su Majestad, con el padre de nuestro autor sobre cobranza de 885.112 maravedís $^{\text {G4. }}$ Y en 1608 el mismo Soria Galvarro se obliga a favor de Mateo de Herrera - ¿algún pariente de Isabel de Herrera?, mercader, por 2.300 reales tomados a préstamo para pagarlos en dinero de contado o en vino de sus heredamiento de Torre de las Arcas ${ }^{65}$. "¿Moriría su padre por entonces? - se pregunta Rodríguez Mofino-. Si así fué, la situación económica de la casa tuvo un trastorno muy grave a causa de estar el Tesorero completamente arruinado. Hernando mismo nos lo dirá en unos versos de la Epistola (...):

... la estrecheza

en que dexo mi padre mi fortuna

reducida a la vltima pobreza

Quizás eso fuera lo que le obligó a salir de Sevilla — sigue conjeturando- . Entre 1608 y 1615 muy poco sabemos de nuestro escritor. (...) Tal vez permaneció en Sevilla hasta que marchó a Roma en calidad de ayo de los hijos del Embajador Conde de Castro" ". No se equivocaba Rodríguez Moñino al dar crédito a estos versos, pues, como veremos, la situación que en ellos se describe parece corresponderse con la realidad. Debieron ser años difíciles en la vida de Soria Galvarro, pues a las dificultades económicas y a la muerte del padre, que, según parece, debió fallecer entre 1607 y 1609, hay 
que sumar otra adversidad: a comienzos de 1607 había fallecido repentinamente su gran amigo el poeta Francisco de Medrano ${ }^{67}$, al que también recuerda en esta epístola.

Ese mismo año de 1607 tras la quiebra del banco público de Pedro de la Torre Espinosa, Hernando de Soria el Viejo, esto es, el padre de nuestro autor, adquirió en pública subasta una heredad llamada Torre de las Arcas, situada en el término de Bollullos de la Mitación, es decir, en el Aljarafe sevillano, y otra, llamada Torreblanca, en 17.000.000 maravedís. Parece que murió poco después, heredando, así, la propiedad de Torre de las Arcas su hijo Hernando de Soria Galvarro, según nos informa Antonio Herrera García - aunque, como se ha dicho, sin sospechar que se trata del poeta sevillano ${ }^{68}$ - . Pero, como también explica éste, "estos Soria no consiguieron levantar las hipotecas que pesaban sobre la heredad y, acuciados con nuevas deudas, el hijo se vio obligado a vender la mitad de la misma y, aún no siendo esto suficiente, también los bienes de éste fueron incautados por un concurso de acreedores y Torre Arcas pasó a un nuevo dueño" "69. La documentación que sobre ello habíamos hallado nosotros mismos en el Archivo Histórico de Protocolos de Sevilla da noticia de la venta en pública subasta no sólo de ésta, sino también de otra, situada cerca de la ciudad de Sevilla y comprendida en su término, que en los documentos que hemos manejado recibe la denominación de heredad y huerta de la Fuente del Arzobispo. Ignoramos si se trata de la misma propiedad que en la documentación estudiada por Antonio Herrera García se consigna como Torreblanca o de otra distinta. Unos y otros documentos difieren también algo en la fecha del remate de la primera, que los consultados por dicho estudioso sitúan en 30 de diciembre de $1609^{70}$. Por los del archivo de protocolos sevillano consta que el 21 de noviembre de 1609, a petición de algunos de los acreedores de los bienes de los herederos de Hernando de Soria el Viejo, el teniente de asistente de la ciudad manda que se den los pregones pertinentes para la venta en pública almoneda de ambas heredades, con todos los esquilmos correspondientes a ese año, tanto pendientes como cogidos, "que quedaron por fin y muerte del d[ic]ho Her[ana]do de Soria el Biejo y agora posee el d[ic] ho Her[an]do de Soria Galbarro" "y que el 15 de enero del año siguiente la heredad de Torre de las Arcas se remató en 30.000 ducados y la de la Fuente del Arzobispo, en 5.321 ${ }^{72}$.

Rodríguez Moñino situaba el nombramiento de nuestro autor como ayo de los hijos del conde de Castro, don Francisco Ruiz de Castro y Portugal, embajador de España en Roma, y su marcha a esta ciudad entre 1608 , en que todavía se hallaba en Sevilla, y 1614, ya que el mayor de los hijos del conde habla nacido en $1613^{73}$. No obstante, es posible que Soria 
Galvarro permaneciera aún en Sevilla a finales de 1609 ó principios de 1610. En 1619, tras haber "salido inciertas" dos vacantes con las que previamente había sido agraciado por Su Santidad, obtiegne la chantría de Córdoba, a la que también aspiraba Góngora. Adviértase que el conocimiento del año de su nacimiento permite concluir que la epístola escrita desde Roma a su primo Lucas, en la que dice tener más de cuarenta años, fue compuesta después de 1613 y antes del 3 de julio de 1620 , en que consta que su autor se hallaba ya en Córdoba ${ }^{74}$. Juan Francisco Andrés de Ustarroz afirma que más tarde fue nombrado capellán de honor de Su Majestad ${ }^{75}$, pero hasta ahora nada se sabe con certeza de los últimos años de vida del poeta. Ignoramos, por tanto, si finalmente pudo disfrutar del tan ansiado retiro:

(...) en oiendo la Misa me saliera a hazer exerciçio la mañana, despues con lentos pasos me boluiera;

$y$ antes que suene a Nona la campana me hallara en el claustro recogido y a la mesa boluiera con mas gana.

Si a la mañana no vuiesse salido por destemplança de aire, o porque al sueño diesse lo que escriuiendo auia perdido.

hecho de mis acciones libre dueño a la tarde al vezino campo iria contento de exercicio mas pequeño

$y$ las oras tal vez ${ }^{76}$ diuertiria con aquella (de libros ya cansado) onesta y religiosa compania.

Tan adelante en esto a caminado qual suele nuestro vago pensamiento que el sitio a ya $"$ y lugar determinado.

Sera pues, si te plaze, aquel conuento que tres millas la gran ciudad vezina tiene, y sobre vn collado hermoso assiento

Do ve el mudo silencio la ruina de Italica desecha que conserua rastros de la alta magestad latina, y el grande Anfiteatro a quien reserua forma el tiempo y assientos leuantados mas cubiertos de malua y de vil ierua

Acuerdome de estar alli sentados muchas vezes Medrano y yo viniendo de su hazienda cerca aunque cansados

y alguna solitaria cabra viendo paçer aquel teatro que algun dia tanta gente vio en si y festiuo estruendo 
de aquella muda soledad salia concento y voz que nos hablaua clara y que a filosofar nos persuadia este sitio por ti agora buscara y en memoria del caro y dulçe amigo el campo dilçemente triste amara.

Vinierasme tu a ver, $y$ alli contigo de $\mathrm{mi}$, o quan larga istoria refiriere, y lo mismo hizieras tu conmigo. repasaranse dende la primera

Ninez nuestra las cosas que an pasado sin reseruar las ${ }^{78}$ de la edad postrera

Despues tal vez a estudio agreste a la vejez la agricultura grata remitiera la cuerda a mi cuidado.

Quien no con esto el corazon dilata y de graue congoxa o de tristeza si le assalta tal vez no le rescata.

Bastame a mi saber que la estrecheza de la vida mortal esperar no osa que se viua a plazer y con largueza.

Aquella sera pues vida dichosa que de grandes dolores careciere y de tristeza o soledad penosa

Que dentro de si misma recogiera toda su pretension y a los engafios de la esperanza nunca puerta abriera.

Que rica de consejo y dessengaños el jubenil error y desconsierto de aquellos ya presipitados afios mira como segura desde el puerto. ${ }^{79}$ 


\section{NOTAS}

1 «Nuevos datos para la biografla de Juan de Jáuregui: La primera noticia documental sobre sus estudios" (Inédito).

2 Así en la única edición que conocemos de esta composición, la de Rodríguez Mofino (RODRfGUEZ MOÑINO, Antonio, "Hernando de Soria Galvarro (Dos poesías inéditas)", en Melages a la memoire de Jean Sarrailh, vol. II, Paris, Centro de Recherches de l'Institut d'Etudes Hispaniques, 1966, págs. 289-293), pero, atendiendo al sentido, parece errata por upuertos.

3 En la ed. de Rodriguez Mofino: "pos», que parece errata, bien de imprenta, bien de copista.

4 prometerte: atendiendo al sentido, parece errata, bien de imprenta, bien de copista, por uprometermes.

5 Art. cit., págs.289-292.

6 Ibid., pág. 290.

7 Las Indias en la poesta sevillana (lirica, epistolar y sattrico-buelesca) del Siglo de Oro (Tesis doctoral inédita).

8 Al decir composición de tema heroico no nos referimos a los grandes poemas épicos, sino a lo que Cristóbal Cuevas ha definido como uuna poesía de exaltación, cantada en tono entusiasta, con el deseo prebarroco de hacernos sentir la emoción de lo sublimes («Introducción", en HERRERA, Fernando de, Poesia castellana original completa, ed. Madrid, Cátedra, 1985, pág. 47).

9 Art. cit., págs. 281 y 288.

10 Sobre el estado de la cuestión, véase el citado artículo de Rodríguez Monino, en el que se recogen las noticias biográficas conocidas hasta la fecha.

11 Vid. Archivo Histórico de Protocolos de Sevilla (en adelante, AHPS), ofic. 21, libro $9^{\circ}$ de 1590 leg. 14.376), fols. $695 \mathrm{v}^{\circ}-698 \mathrm{r}^{\circ}$ y libro $1^{\circ}$ de 1591 , fol. $544 \mathrm{r}^{\circ}$-vo.

12 RODRIGUEZ MOÑINO, A., art. cit., pág. 282.

13 Aung: «aunque», alegrara: Así en la edición de Rodriguez Mofiino, pero, atendiendo al sentido, parece errata por "alargara".

14 Ibid., pág. 290.

15 «<Hernandos En vey[n]te y ocho días del mes de hebrero/ de mill y quinientos y setenta y tres afios bavti-/zé yo, el bachiller Sabastián (sic) Román, cura/ de la yglecia del Sefior San Lloreynte (sic), a Hernando,/ hijo de Fernando de Soria y de dofia Maria del Jaso, su mujer. Fue("ron", va tachado) su("s", va tachado) padrino("s", va tachado) don Anto-/nno (sic) Anríques (sic) Pinmentel (sic), v[e]z[in]o de la sivdad/ de Santo Domingo/ El b[achi]ll[e]r Román [Rúbrica]». (Archivo Parroquial de San Miguel de Sevilla (en adelante, APSMS, conservado en el de la Magdalena de

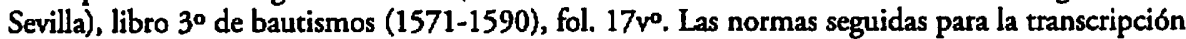
de éste y cualquier otro documento reproducido en el presente estudio son las siguientes: respetamos la ortografla del texto y conservamos los casos de seseo y ceceo, si bien para facilitar su lectura actualizamos el uso de maynisculas, así como la puntuación; suplimos la acentuación; resolvemos las abreviaturas; separamos las formas unidas, aunque mantenemos las elisiones; ponemos entre corchetes lo que suplimos en el texto para su comprensión, incluida la resolución de abreviaturas; entre paréntesis, las śllabas o palabras que se repiten o constituyen un ańadido inútil debido a una posible distracción del escribano, asi como las notas explicativas sobre cualquier particularidad del texto; $y$ entre paréntesis angulares, lo que aparece al margen o entre líneas).

16 Vid. AGI, Indiferente, 741, núm 117 (s.f.).

17 Vid. ibid., Santo Domingo, 58, ramo 5, núm. 74 (s.f.) e Indiferente, 113, núm. 76 (s.f.). Sobre Francisco Enriquez Pimentel y otros miembros de la familia, puede verse Escribanfa, 36 B, núm. 5 y AHN, Diversos, 36, doc. 29. 
Vid. ibid., Patronato, 172, ramo 20 y 173, núm. 2, ramo 11.

Cfr. HERRERA GARCIA, Antonio, Torre Arcas. Biografia de un latifundio sevillano, Córdoba, Monte de Piedad y Caja de Ahorros de Córdoba, 1989, pág. 83.

20 APSMS, libro $3^{\circ}$ de bautismos (1571-1590), fol. 49\%.

21 El 12 de enero de 1609 el doctor Lucas de Soria, canónigo de la Santa Iglesia de Sevilla y vecino de la collación de San Vicente, otorgó un poder a dos personas que por entonces iban a la provincia del Perú para que pudieran demandar, recibir y cobrar de Juan de Agüero, residente en la ciudad de Lima, lo procedido de ocho cajones de libros que contenian cuatrocientos cuerpos de libros, todos intitulados De la imitación de Cristo. Parte tercera, que le habia entregado para que se los vendiese, o para que vendieran los que restaran por vender y le enviaran lo cobrado (Vid. AHPS, oficio 21, libro $1^{\circ}$ de 1610 (leg. 14.466), fols. 478 $\mathrm{r}^{\circ}-479 \mathrm{r}^{\circ}$ ).

22 Pedro Fernández de Soria e Isabel Galvarro tuvieron varios hijos además de Lucas: Lucrecia, bau-

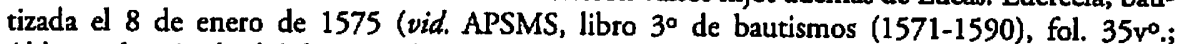
Aldonza, bautizada el 4 de mayo de 1577 (vid. ibid., fol. $57 v^{\circ}$ ); Petronila, bautizada el 18 de julio

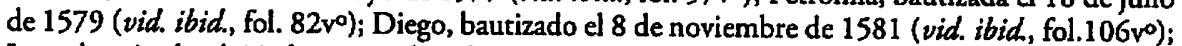
Juan, bautizado el 19 de septiembre de 1583 (vid. ibid., fol. 1250\%); María, bautizada el 12 de agosto de 1585 (vid. ibid., fol. 157 ${ }^{\circ}$ ); Pedro, bautizado el 9 de febrero de 1588 (vid. ibid., fol. $187 \mathrm{r}^{\circ}$ ) y Antonia, bautizada el 2 de agosto de 1589 (vid. ibid., fol. 209 $\mathrm{r}^{\circ}$ ).

Entre las partidas de matrimonio conservadas en el Archivo Parroquial de San Miguel de Sevilla, no hemos encontrado registrado ninguno de estos dos matrimonios. Consta, en cambio, en 1572 el de dos criados de Fernando de Soria, moriscos de Granada. En el mismo archivo consérvanse también varias partidas de bautismo y matrimonio de esclavos de los Soria (Vid. infra pág.

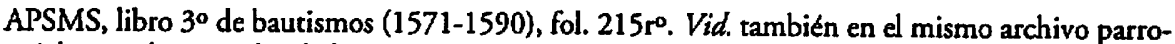
quial otras dos partidas de bautismo en las que el padre de nuestro actuó como testigo. Una, de 1592 y otra anterior, de 1582 , de una de sus esclavas (Vid. ibid., fol. $112 \mathrm{v}^{\circ}$ y libro $4^{\circ}$ de bautismos (1590-1604), fol, 20 $\left.r^{\circ}\right)$.

25 Vid. op. cit., págs. 83-84 n. 3. Vid. también pág. 36.

26 Vid. AGI, Contratación, 145, núm. 19 (s.f.).

27 No es posible localizar la partida de defunción, ya que en el archivo de dicha parroquia no se conservan las anteriores al ano 1630.

28 No hemos podido localizar este documento debido al mal estado del libro correspondiente a esas fechas, que está desordenado, deteriorado y falto de algunos cuadernillos.

29 Vid. Archivo Parroquial de San Salvador de Sevilla(en adelante, APSSS), libro $2^{\circ}$ de bautismos (1530-1540), fol. 198 ${ }^{\circ}$. (Aunque en la partida de éste se lee que fue bautizado "En ("lu", va tachado) martes doze de hebreto de quini[ent] os y treinta y siete (sic) afiosm, no cabe duda de que lo fue en 1538 y que el afio consignado en ella se debe a un lapsus, aunque éste no haya sido subsanado como en el caso del día de la semana. Así se desprende del hecho de que las partidas de bautismo correspondientes a 1538 dan comienzo tres folios antes, en el fol. $195 r^{\circ}$ y que las partidas inmediatamente anteriot y posterior a la que nos ocupa corresponden a 1538).

30 «En lunes ocho días del mes de deziembre, afio de mill e/ <Marla> quinientos y treinta e nueve ấos, baptizé yo, J[uan] Benites,/cl[ér]igo cura, a Marla, hija de Juan Galuarro y de doñal Ysabel, su muger. Fueron compadres el dottor Fran[cis]co/ de Vargas y don Gerónimo [en blanco] y el p[ri]or Hernando Pé-/res y (y) el jurado [en blanco] Ortíl Joha[nes]/ Beni[tes] [Rúbrica]» (Ibid., fol. $\left.231 r^{\circ}\right)$.

31 Vid. APASSS, libro $3^{\circ}$ de bautismos (1540-1552), fol. 114 $\mathrm{r}^{\circ}$.

32 Vid. ibid., fol. 163\%०.

33 Vid. ibid., fol. 186 ${ }^{\circ}$. Uno de sus padrinos fue cierto Luis de Mújica, probablemente deudo del 
Melchor de Mújica, sobrino de Juan Galvarro, al que éste -como veremos enseguida- nombra como albacea de su testamento.

Para las noticias sobre los Galvarro referidas hasta aqui vid. AGI, Justicia, 1049, num. 5, ramo $1^{\circ}$ (s.f.). Sobre la confirmación de la tutela puede verse también AHPS, oficio 20, libro $1^{\circ}$ de 1551 (leg. 13.481), fol. 256r'.

Vid. AGI, Indiferente,1092, núm. 129 (s.f.), 1092, núm. 129 (s.f.), 424, libro 21, fol. 90 r $^{\circ}$ Contratación, 4325, núm. 1.

36 Vid. ibid., Indiferente, 422 , libro 16 , fol. $289 \vee^{\circ}$.

37 Vid. ibid, libro 17 , fols. $83 \mathrm{r}^{\circ}-84 \mathrm{r}^{\circ}$.

38 Vid. ibid., Justicia, 742, núm. 3 (s.f.).

39 Vid. APSSS, libro $3^{\circ}$ de bautismos (1540-1552), fol. 490.

40 Vid., AGI, Indiferente, 423, libro 20, fols. 599v0-600vo.

41 Vid. ibid., fols. 671vo-672\%०.

42 Vid. ibid., Justicia, 742, núm. 3 (s.f.) e Indiferente, 423, libro 20, fols. 621 ro y 639ro.

43 Vid. ibid., Indiferente, 424, libro 21, fols. 49vo-50 ro.

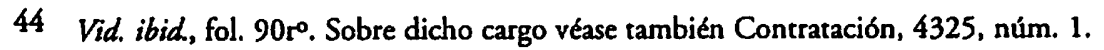

45 AGI, Indiferente, 424, libro 21, fols. 146\% $148 \mathrm{r}^{\circ}$.

46 Vid. ibid, fols. 164vo-166r

47 Vid. ibid., fols. 179v-180vo.

48 Vid. ibid., libro 22, fol. 29v0.

49 Vid ibid, libro 22, fol. 40 ${ }^{\circ}-\mathrm{v}^{\circ}$.

50 Vid. ibid, Justicia, 1010, núm. 3, ramo $2^{\circ}$ (s.f.).

51 Vid. ibid., 1049, núm. 5, ramo $1^{\circ}$ (s.f.); Indiferente, 424, libro 22, fols. $276 \mathrm{r}^{\circ}$ y $487 \mathrm{v}^{\circ}$ y Patronato, 281, núm. 1, ramo $90^{\circ}$.

52 Vid. AHPS, oficio 20, libro único de 1550 (leg. 13.480). (Este documento, que se halla incompleto, se encuentra en un folio sin foliar en el que se observan unos trazos verticales que cruzan la escritura, de todo lo cual y de su localización dentro del libro de protocolos parece deducirse que este folio se utilizó para separar dos cuadernillos de dicho libro, el cual se encuentra desordenado, incompleto y muy deteriorado).

53 Vid. ibid., libro $1^{\circ}$ de 1551 (leg. 13.481), fols. 256ro-257 $\mathrm{r}^{\circ}$.

54 Vid. Catdlogo de Pasajeros Indias durante los siglos XVI, XVII y XVIII, vol. V, Sevilla, Ministerio de Cultura, 1982, núm. 25696 Contratación, 5537, libro 3, fol. 29.

55 Así, entre 1576 y 1594 se bautizaron once esclavos del padre de nuestro autor; entre 1573 y 1593, cuatro esclavos de Pedro Fernández de Soria, de la madre de uno de los cuales se conserva también la partida de matrimonio; entre 1586 y 1592 se registra el bautizo de dos esclavos de doha Leonor de Soria y uno, de donia Marfa de Soria, probablemente las tias del escritor (Vid. APSMS, libro $1^{\circ}$ de matrimonios (1558-1577), fols. $28 \mathrm{v}^{\circ}, 43 \mathrm{r}^{\circ}$ y $45 \mathrm{r}^{\circ}$; libro $3^{\circ}$ de bautismos (1571-1590), fols. $19 \mathrm{r}^{\circ}, 47 \mathrm{r}^{\circ}$ y $\mathrm{v}^{\circ}, 50 \mathrm{v}^{\circ}, 57 \mathrm{r}^{\circ}, 99 \mathrm{v}^{\circ}, 112 \mathrm{v}^{\circ}, 159 \mathrm{r}^{\circ}, 164 \mathrm{v}^{\circ}, 168 \mathrm{r}^{\circ}, 170 \mathrm{r}^{\circ}, 176 \mathrm{v}^{\circ}$,

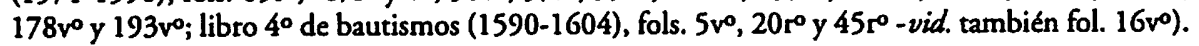
Vid. AHPS, ofic. 21, libro $9^{\circ}$ de 1590 (leg. 14.376), fols. 454ro-456 ${ }^{\circ}$.

57 Vid. AGI, Contratación, 145, núm. 19 (s.f.).

58 Cfr. op. cit., págs. 83-84 n. 3.

59 Vid. AHPS, ofic. 21, libro $6^{\circ}$ de 1593 (leg. 14.401), fol. $195 \mathrm{r}^{\circ}$-vo. Las escrituras otorgadas por Hernando y Pedro Fernández de Soria que se conservan en el AHPS son numerosas. Hallánse también varias otorgadas por Lucas de Soria, entre las que destacamos la siguiente: el 12 de enero 
de 1609 el doctor Lucas de Soria, canónigo de la Santa Iglesia de Sevilla y vecino de la collación de San Vicente, otorgó un poder a dos personas que por entonces iban a la provincia del Perú para que pudieran demandar, recibir y cobrar de Juan de Agüiero, residente en la ciudad de Lima, lo procedido de ocho cajones de libros que contenfan cuatrocientos cuerpos de libros, todos intitulados De la imitación de Cristo. Parte tercera, que le habia entregado para que se los vendiese, o para que vendieran los que restaran por vender y le enviaran lo cobrado (Vid. ibid, ofic. 21, libro $1^{\circ}$ de 1610 (leg. 14.466), fols. 478 $\mathrm{r}^{\circ}-479 \mathrm{r}^{\circ}$ ). Sobre Lucas véase también Archivo de la Catedral de Sevilla, secc. IX, leg. 185, núm. 13 (s.f.) y leg. 108, núm. 1.

Vid. AGI, Contratación, 724, núm. 1, ramo $4^{\circ}$ (s.f.).

61 Vid. RODRfGUEZ MARÍN, Francisco, "Lope de Vega y Camila Lucinda», Boletín de la Real Academia Española, I (1914), págs. 275-276.

Vid. AGI, Contratación, 145, núm. 19 (s.f.).

Vid. VRANICH, Stanko B., «El negociante tinerfeño Gaspar de Arguijo (1532-1594). Historia de un exito", Anuario de Estudios Americanos, 26 (1980), pág. 611.

Vid. AGI, Contratación, 751, núm. 19.

Vid. RODRIGUEZ MOŇINO, A., art. cit., pág. 284.

Ibid., pág. 284.

67 Vid. ALONSO, Dámaso, "Vida y obra de Medrano, I», en Obras completas, vol. III (Estudios y ensayos sobre literatura. Segunda parte), Madrid, Gredos, 1974, pág. 204.

Vid. op. cit., págs. 31-32 y 159-160. Al parecer en la carta de venta real otorgada el 20 de abril de 1607 se dice que Hernando de Soria es vecino de la collación de San Marcos (vid. pág. 159, doc. núm. 2). Nos consta que el 15 de abril de 1606 nuestro autor, que a la sazón era vecino de dicha collación, arrendó hasta finales de ese mismo afio unas casas "que son en la calle de don Andrés de Monsalves y frontero de la de Uceda, que lindan con casas de Juan Farfán, clérigo, y otros linderos y por otro nombre se llama la calle del Postigo de San Antón, collación de San Vicente (...) a razón cada año de ciento y ocho ducados, a razón cada mes de nueve ducados" (AHPS, ofic. 21, libro $1^{\circ}$ de 1606 (leg. 14.454), fol. 884r $\mathrm{r}^{\circ}-\mathrm{v}^{\circ}$ ).

69 Op. cit., pág. 83.

70 Cfr. ibid., pág.34. Para más detalles sobre las vicisitudes de esta propiedad, véase también págs. 32-36 y 161 .

71 AHPS, ofic. 21, libro $4^{\circ}$ de 1609 (leg. 14.465), fol. 787ro. Véase también fols. $786 r^{\circ}$ y $787 \mathrm{v}^{\circ}$ $801 r^{\circ}$.

72 Vid. ibid., fols. $482 \mathrm{r}^{\circ}-486 \mathrm{v}^{\circ}$.

73 Cfr. art. cit., pág. 285.

74 Vid. ibid., pág. 286. Por el momento sólo podemos añadir la noticia de un nuevo documento a lo contenido en el estudio de Rodríguez Mofino en relación a la etapa cordobesa de nuestro autor: en 20 de noviembre de 1624 el padre maestro fray Francisco Manuel Muniera, conventual del convento de la orden de Nuestra Sefiora de la Merced de Córdoba, en nombre de dofía Isabel Ana de Muniera, vecina de la villa de Jabalquinto, ororga carta de pago por mill reales que dice haber recibido "del s[efi]or don F[e]r[nan]do Galbarro de Soria, chantre en la Santa Yglesia de Cór[do]ua”, por cuenta de dos mill reales que le debfa su hijo, fray Estevan de Muniera, obispo de Cefalú, en el reino de Sicilia (Archivo Provincial de Córdoba, secc. Protocolos, ofic. 12, leg. 101, fol. $\left.905 \mathrm{r}^{0}-\mathrm{r}^{\circ}\right)$.

75 Vid. RODRIGUEZ MOÑINO, A., art. cit., pág. 285.

76 En la ed. de Rodriguez Monino: «verw, que parece errata, bien de imprenta, bien de copista.

77 En la edición de Rodriguez Monino: "aya", tal como probablemente se halla en el manuscrito. Entendemos que la transcripción correcta es ua yau, esto es, "ha ya", y no "ayan, es decir, «hayan. 


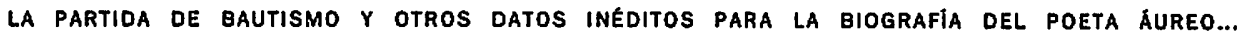

No obstante, es posible que no se trate de una mala interpretación del editor, sino de una errata de impreta.

78 En al referida edición: «reseruarlas». Como en el caso anterior, suponemos que así debe aparecer escrito en el manuscrito, pero asimismo creemos que ha de transcribirse como lo hacemos, ya que entendemos que aqul "las" no funciona como pronombre sustitutivo de ulas cosas que an pasadon, sino que forma parte del complemento directo de ureseruarn, que no es otro que "las [cosas] de la edad postrera". (Aunque en el momento de escribir estas páginas no hemos podido contar con una reproducción del manuscrito, tenemos en proyecto ofrecer una nueva edición de esta epistola. El hecho de no disponer de una reproducción del texto manuscrito nos impide pronunciarnos sobre algunos otros pasajes que parecen ofrecer ciertas dificultades y en los que, por tanto, seguimos la única edición con la que contamos actualmente).

79 RODRfGUEZ MOÑINO, A., art. cit., págs. 292-293. 